\title{
PRÓLOGO
}

\section{DESDE LAS FUENTES: APROVISIONAMIENTO Y CIRCULACIÓN DE MATERIAS PRIMAS EN PERSPECTIVA REGIONAL}

\author{
Ariel D. Frank ${ }^{1}$, Fabiana Skarbun ${ }^{1}$ y Manuel E. Cueto ${ }^{1}$
}

\begin{abstract}
En Sudamérica se ha producido durante los últimos años un notable aumento en el número de investigaciones arqueológicas enfocadas en el estudio de los afloramientos y las fuentes minerales, que involucran diferentes escalas sociales, cronológicas y espaciales. Estas son fundamentales para abordar los análisis de la tecnología de las sociedades pasadas que consideren una perspectiva dinámica del manejo de los recursos tanto como para discutir aspectos vinculados con la circulación de materias primas y artefactos, los distintos usos del paisaje y la movilidad.

Las fuentes de aprovisionamiento de materia prima constituyen el punto inicial de los procesos de producción de artefactos -que incluyen diferentes estrategias para la adquisición, transporte, almacenamiento, conservación, transformación, uso y descarte-. En este sentido, los recursos son seleccionados para producir elementos útiles en distintas prácticas cotidianas, teniendo en cuenta las características tanto de las fuentes -accesibilidad, disponibilidad, visibilidad, territorialidad, distancia, etc.- como de los minerales allí presentes -tipo, calidad, color, tamaño, dureza, etc.-. Al mismo tiempo, son de gran relevancia distintos factores sociales que influyen en la toma de decisiones sobre la elección de dichos recursos, como diversos aspectos simbólicos involucrados en la vida de las sociedades que adquirieron y/o utilizaron estos recursos. Los recursos pueden ser aprovechados por la comunidad en su conjunto o por un sector restringido de la misma.

Los trabajos publicados en este número fueron inicialmente presentados en el simposio "Desde las fuentes: estudios de selección y aprovisionamiento de minerales. Implicancias en la producción lítica, alfarera, metalúrgica y de manifestaciones rupestres", que coordinamos en el marco del XIX Congreso
\end{abstract}

Nacional de Arqueología Argentina en agosto de 2016. El simposio procuró ser un espacio para la exposición y discusión de diversas propuestas teóricas, planteos metodológicos y casos de estudio sobre las prácticas sociales relacionadas a la gestión de los recursos minerales, su naturaleza y distribución. En este sentido, nuestras expectativas estuvieron centradas en discutir las distintas maneras en que se puede abordar el estudio de las fuentes de aprovisionamiento. Esto se llevó a cabo a partir de la reflexión sobre la existencia de problemáticas en común que atraviesen geografías y materialidades e integren diversas metodologías, intentando construir lazos entre ellas. Vimos con satisfacción que el estudio de las formas de selección, abastecimiento y circulación de materias primas se encuentra en un momento de gran desarrollo. Este involucra enfoques que están fuertemente instalados en los modos de hacer de la disciplina. También observamos el desarrollo de perspectivas innovadoras y una creciente sofisticación de las herramientas metodológicas, lo que permite reformular nuestros trabajos e incorporar distintas preguntas o puntos de vista. Las discusiones planteadas a lo largo del encuentro demostraron que existe la necesidad de fortalecer los marcos de interpretación sobre los que construimos conocimiento arqueológico. Es necesario robustecer los aspectos que se vinculen con la agencia de las sociedades humanas, para comprender la gran cantidad y diversidad de factores que actúan en los procesos de aprovisionamiento y traslado de rocas y artefactos al igual que la multiplicidad de actividades llevadas a cabo en los espacios de abastecimiento. Asimismo el estudio específico de fuentes y canteras demostró la necesidad de replantear o ampliar algunas terminologías comúnmente empleadas, al igual que las metodologías de registro y relevamiento desarrolladas,

\footnotetext{
${ }^{1}$ Consejo Nacional de Investigaciones Científicas y Técnicas (CONICET)/ División Arqueología, Facultad de Ciencias Naturales y Museo, Universidad Nacional de La Plata. Laboratorio 107, Edificio ANEXO Museo. 60 y 122 s/n (1900), La Plata, Buenos Aires, Argentina.
} 
que no consideraban las particularidades de este tipo de sitio. En este sentido, creemos que los trabajos aquí publicados son buenos ejemplos del estado de la cuestión en estas materias.

Entre las problemáticas abordadas en este volumen existe un énfasis en la comprensión de la procedencia y circulación de recursos. Para el primero de estos aspectos los investigadores complementan perspectivas arqueológicas con estudios geoquímicos, puesto que estos pueden brindar información precisa sobre el origen de los recursos. Por otra parte los autores consideran distintos mecanismos y contextos sociales que les permiten explicar la circulación de las personas, los recursos y los bienes tanto como la relación entre distintas regiones cercanas o distantes.

Por ejemplo Cristina Bellelli y colaboradores discuten la complementariedad entre los ambientes del bosque continental, el ecotono y la estepa de norpatagonia considerando la circulación de obsidianas en sitios arqueológicos de las provincias de Río Negro y Chubut, en Argentina. Para ello aplican análisis por ICP-MS, comparando los resultados con la información disponible para las fuentes de Patagonia norte y central. Esto les permitió identificar la explotación de diez fuentes que habrían funcionado como nodos de distribución en el marco de circuitos de movilidad de los grupos al interior del bosque y entre el bosque y la estepa. A su vez pudieron reconocer la explotación de esta materia prima desde el Holoceno temprano.

En tanto, Roberto Campbell y colaboradores abordan, para Isla Mocha en el sur de Chile, los análisis de aprovisionamiento de obsidiana, restos metálicos y cuentas de turquesa en el marco de un proceso complejización social entre el 1.000 y el 1.700 d.C. Estos recursos, que no están disponibles localmente, fueron recuperados en numerosos contextos posibilitándoles discutir la relación de las poblaciones isleñas con aquellas del continente. Con el propósito de evaluar la procedencia de estos minerales aplican diversas técnicas como ICP-MS, XRF, XRD, PIXE y SEM-EDS. El análisis contextual junto con los resultados composicionales les permiten plantear la existencia de redes de intercambio a larga distancia en un escenario de gran movilidad de bienes y recursos, empleados como bienes de prestigio por ciertos individuos y comunidades para el período analizado.

Otra problemática remite al estudio de los procesos de producción artefactual a partir de los restos identificados en sitios arqueológicos. Para ello se busca relacionar las evidencias provenientes de sitios que tienen diversas funcionalidades con aquellas relevadas en las fuentes. Manuel Cueto y colaboradores analizan las estrategias de aprovisionamiento, producción y consumo realizadas con obsidiana para sitios de la Meseta Central de la provincia de Santa Cruz. El estudio incluye un enfoque que articula el análisis tecnomorfológico y funcional de los artefactos junto al análisis por ICP-MS. Esto les permite integrar los resultados de una muestra amplia con los antecedentes de explotación de esta roca en la meseta y formular propuestas en cuanto a su circulación en la región. A partir de diferencias en la intensidad de uso y en los procesos productivos implementados, establecen dos momentos para la explotación de esta materia prima dentro de una extensa secuencia de ocupación que se inicia en el Pleistoceno Final.

Un tercer enfoque remite a la caracterización detallada de las fuentes de aprovisionamiento y el análisis de los materiales identificados en ellas. Este permite evaluar en profundidad prácticas tecnológicas vinculadas al abastecimiento de rocas, la estructuración del espacio en las fuentes en relación a las actividades de talla y el desarrollo de actividades no necesariamente referidas a la obtención de recursos pero desarrolladas en el mismo ámbito. Desde esta perspectiva Federico Bobillo examina la fuente POZAC en Antofagasta de la Sierra, provincia de Catamarca, Argentina, para comprender los procesos de producción de artefactos líticos a nivel microrregional, poniendo énfasis en los métodos y las técnicas empleadas durante las primeras etapas de la manufactura. Evalúa las estrategias tecnológicas implementadas combinando el análisis tecno-tipológico y una perspectiva distribucional. Este abordaje le posibilitó identificar locus de talla específicos dentro del espacio de las fuentes, comprender los criterios seguidos por los grupos durante el proceso de selección y talla del recurso lítico y establecer que dicha fuente habría sido explotada al menos desde el Holoceno Temprano.

Para finalizar, quisiéramos agradecer a los investigadores que participaron del Simposio y de este volumen compartiendo sus valiosas contribuciones y discusiones. Asimismo a los revisores que con sus comentarios y observaciones enriquecieron los trabajos. Por último, agradecemos a los editores de Chungara, por su esfuerzo y apoyo durante este proceso. 